\title{
8 Translation of Languages
}

We speak of the opposition of philosophical theories if the set of propositions formed by the conjunction of the propositions of both theories is inconsistent. This presupposes that both theories are expressed in the same language. If this is not the case, we speak of the opposition of styles, methods, or attitudes. True, but if a speaker is bilingual, this does not hold (Cesana 2000). This is a definite possibility, for bilingualism and multilingualism have become quite widespread today. Besides, translation does not simply occur between two languages or cultural spheres. It is shaped by a continuous cultural and media transformation process between different semiotic registers (Ott and Weber 2019). Comparative philosophy has become necessary, just like comparative literature (Hamburger 1956; Panikkar 1988; Sweet 2009). The translatio linguarum is an essential structure of the translatio studiorum (Gregory 2012, 19). Let us think of the work done by Petrus Venerabilis in twelfth-century Toledo that, after the turn of the millennium, had become the center of translations from Arabic to Latin with the intermediation of Hebrew. Translation became the necessary premise for mutual understanding (Gregory 2016, 31). Translators found expression in grafts that punctuated cultures while provoking exogamic marriages, assiduous intertwining, and exchanging experiences and values among diverse civilizations. Hence, each culture was born by exploiting the inheritance of other cultures, which have been made their own, transcribed, translated, and interpreted in new contexts and languages (Gregory 2016, 1).

This chapter is about the conditions of the possibility of contemporary translation approaches to philosophical texts. It insists on the tenets of the centrality of text and the transmission of texts and studies.

\subsection{Bilingualism and Multilingualism}

What makes education unique is not a canon of scattered texts but familiarity with traditions and their plurality. "Readers, not professors, make canons.... A space outside the school, where the canon is selected: the market" (Moretti 2013, 67-68). This implies that if a research project is "focused on a canonized device," then "in the noncanonical universe, it can only discover ... the absence of the device, that is of the canon" (Moretti 2013, 87). Although English has become indispensable in its function as auxiliary international language-as Umberto Eco (1993) has put it-the lingua franca of our days, no nation-state can afford to lose its linguistic variety. In the humanities, everything speaks in favor of

Ә OpenAccess. (c) 2021 Riccardo Pozzo, published by De Gruyter. (cc))BY-NC-ND This work is licensed under the Creative Commons Attribution-NonCommercial-NoDerivatives 4.0 International License. 
multilingualism. Bilingualism and multilingualism have become "the norm rather than the exception in everyday life of the citizens of the world today" (Li Wei 2010, 1). It is true that language shift is "a gradual process, and can take several generations to complete" (Li Wei 2010, 6). However, for individuals and groups of language users, it has become easy to get "into contact with each other in different ways" (Li Wei 2010, 2) by relying on "contact languages” under the "structural constraints of lexical borrowing, diffusion, and codeswitching." Here we have to look at the "roles of specific languages versus the principles and parameters of Universal Grammar” (Li Wei 2010, 7).

There is a "continuum from a subordinate or compound end to a coordinate end," a continuum that can "at the same time be more subordinate or compound for certain concepts and more coordinate for others, depending on, among other things, the age and context of acquisition" (Li Wei 2010, 9). We talk of audience design based on the negotiation principle that directs speakers to choose the form of one's conversational contribution such that "it symbolizes the set of rights and obligations," which one wishes "to be in force between speakers and addressees for the current exchange” (Li Wei 2010, 11).

The application of computational techniques and visualization technologies in the humanities results in innovative approaches and methodologies for analyzing traditional and new corpora (Zanettin 2014). Language technologies themselves are available in English first. About multilingualism, however, it is thinkable to make better use of new technological approaches, based on increased computational power and better access to sizeable amounts of data, in order to foster the development of deep-learning neural networks, which make human language technologies a solution to the problem of language barriers. As I have shown in chapter 7, research infrastructures such as CLARIN are up and running to promote and facilitate linguistic diversity and multilingualism in the digital sphere, which ought to be "cloud-based and interoperable and provide highly scalable and high-performance basic tools for several language technology applications” (Evans 2018).

A dimension to open up is that of integrational linguistics. We can take up the perspective of languages spoken by migrants, the integration of whom configures new ethnicities (Harris 1998, 2003). We need to boost translation research and its own rules (Kittel et al. 2004-2011; Canullo 2017). Multilingual language policies are the norm in multicultural societies. Multicultural societies have this name insofar as they have accepted "the demand for group-differentiated rights by ethnic and national minorities" (Kymlicka 2011, 327). All groups demand "recognition," whereby Hegel "comes to mind right off, with his famous dialectic of the master and the slave" (Taylor 2011, 93-94). The "one language-one nation ideology of language policy is no longer the only available one worldwide (if 
it ever was)" (Hornberger 2010, 432). Transnational labor migration has replaced earlier processes of "dispersion of populations and the peopling of the world." In fact, "the characteristic form of language change in the modern era is the coming together of languages." The consequence is that the former "relatively egalitarian linguistic diversity, based on small-scale languages whose speakers believe their language to be superior" has been changed into "stratified diversity: local languages are abandoned or subordinated to world languages in diglossic relation" (Hornberger 2010, 434).

In narrative theory (Labov 2001), we talk of "narratives of dislocation" (Baynham and De Fina 2005) and of an "ecology of language," which is "the study of the interaction between any given language and its environment," namely considering "its interaction with other languages in the mind of biand multilingual speakers," together with "its interaction with the society in which it functions as a medium of communication" (Hornberger 2010, 434). The continuum of biliteracy is a model proposed by Nancy Hornberger to situate research, teaching, and language planning in multilingual settings. Biliteracy is "any and all instances in which communication occurs in two (or more) languages in or around writing” (Hornberger 2010, 437). The consequence is that:

one language and literacy is developing in relation to one or more other languages and literacies (language evolution); the model situates biliteracy development (whether in the individual, classroom, community, or society) in relation to the contexts, media and content in and through which it develops (i.e., language environment); and it provides a heuristic for addressing the unequal balance of power across languages and literacies (i.e., for both studying and counteracting language endangerment). (Hornberger 2010, 437)

Research in bilingualism has accumulated an impressive amount of knowledge on lexical and cognitive processing in bilingual individuals, but still not much "about the impact of cross-linguistic and cross-cultural differences on thought processes" (Pavlenko 2010, 362). The latter being a line of research that builds on Benjamin Whorf's (1956) original assumption "that second language (L2) learning-just like socialization-may result in assimilation of new perspectives and conceptual restructuring" (Pavlenko 2010, 365). "Linguistic thinking"maintained Whorf-is "thought insofar as it is linguistic" (Whorf 1956, 67-68). Language-based concepts, in turn, are subdivided into lexicalized and grammaticized concepts. The former "entail lexical encoding of natural objects, artifacts, substances, events, or actions," and the latter "entail morphosyntactically encoded notions such as number, gender, tense, or aspect” (Pavlenko 2010, 365). In this context, the internalization of new concepts "entail adoption of L2 words-and underlying concepts-into the L1 of immigrant bilinguals and learners in language contact situations who perceive the need to emphasize distinc- 
tions nonexistent in the L1 or to refer to new objects and notions specific to the L2 community" (Pavlenko 2010, 369). Immigrants that have become bilingual "tend to retrieve memories in the same language in which they are encoded or at least to report more vividly and with more detail if reporting in the language of the event” (Pavlenko 2010, 381).

Again, the "Chinese Philosophy" article of the Routledge Encyclopedia of Philosophy makes it clear that the way to introduce and to handle concepts in the Confucian tradition differs radically from the Platonic and Aristotelian traditions:

Chinese "categories" (lei) are defined not by the presumption of a shared essence defining natural "kinds," but by an identified functional similarity or association that obtains among unique particulars. Definitions are not framed in the terms of essential features and formal class membership; instead, definitions tend to be metaphorical and allusive, and invariably entail the human subject and human values. (Hall and Ames 1998, sect. 3)

Said in another way, the Chinese cosmic order is best understood as the art of correlating and contextualizing within the eventfulness of the human experience (Ames 2015, 213-214). And if we compare and contrast life in China, Japan, and India, on the one hand, and the West, on the other, "we must recognize that postindustrial advances in technology are both reducing and aggravating differences in our worldviews" (Makkreel 2020, 326-327). From the standpoint of both China and the West, education "promises to help us appreciate where others are coming from, in the fullest sense of that expression" (Blair 2010, 1). The paradigm of multicultural education as "social reconstruction" asserts the "need to reform the institutional structures and schooling practices that maintain the societal status quo" (Grant and Chapman 2008, 1). The role played by the Chinese student of the apologue in chapter 2 is nothing more and nothing less than "intercultural communication," which is a young field of study that deals with "communication between and among people from different cultures" (Cai 2010, xxi) and brings about "cross-cultural entanglements" that often are cause of miscommunication because interlocutors use norms that are socially and culturally different for interpreting others. However, in voluntary contacts, "these issues can be managed by interlocutors who attempt to negotiate meanings and understand the cultural other in a rather symmetrical manner" (Kramsch and Uryu 2011, 212). The important thing is the student imagined in the apologue (see above chapter 2) is bilingual, for she masters both Italian and Chinese and possibly multilingual, for she must have learned English and might as well be able to read Greek and Latin (Li Wei 2010; Gardner and Martin-Jones 2012). 


\subsection{Babel}

Issues of multilingualism and translation can be addressed from both historical and contemporary perspectives. The objective is to gain from the past successful ways of coming to terms with the untranslatability of some words and experiences, affecting intercultural communication quality. The main concepts of contemporary translatology are Translationese, linguistic patterns that tend to make translations more similar to each other than to texts originally written in their target language, and variations that refer to the fact that different types of translations, such as written translations vs. interpreting, display systematic linguistic differences. Tullio Gregory has pointed to the story of the tower of Babel (2016, 66) and the scattering of what used to be a unique language:

Now the whole world had one language and a common speech. As people moved eastward, they found a plain in Shinar and settled there. They said to each other, "Come, let's make bricks and bake them thoroughly." They used brick instead of stone, and tar for mortar. Then they said, "Come, let us build ourselves a city, with a tower that reaches to the heavens, so that we may make a name for ourselves; otherwise, we will be scattered over the face of the whole earth." But the Lord came down to see the city and the tower the people were building. The Lord said, "If as one people speaking the same language, they have begun to do this, then nothing they plan to do will be impossible for them. Come, let us go down and confuse their language so they will not understand each other." So, the Lord scattered them from there over all the earth, and they stopped building the city. That is why it was called Babel-because there the Lord confused the language of the whole world. From there the Lord scattered them over the face of the whole earth. (Genesis 11, 1-9)

History of philosophy ought to consider changes in philosophical languages and in the modes of writing philosophy. Current attention to evolutionism in Asia has brought up great attention to sociobiology and humanities (Kang 2014, 407-417). Today, we talk of "cultural intelligence in virtual cross-cultural interaction" (Presbitero 2016). In seventeenth-century China, we see Matteo Ricci translating the Bible into Chinese (Canullo 2017, 14-16; Pirni 2018, 234). That Chinese characters are the signs of the universal language and their 214 radicals the keys for streamlining the input and the output of every source and target language was the hypothesis advanced as early as 1667 by Athanasius Kircher in his encyclopedic endeavor China illustrata. Kircher was among the first to point out the anatomy of the ancient characters of Chinese (Kircher 1986, 216), following the natural origin

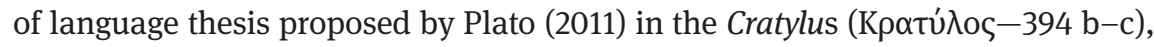
and its corollary of a clavis universalis to be found in hieroglyphics and the Kab-

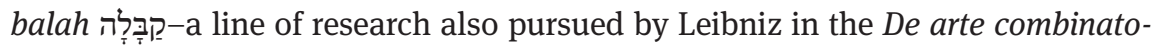
ria (1666; see Eco 1993; Li Wenchao 2014). 
In 1911 in China, the Imperial government started the project of a Civil Code that was based on Roman Law. It was abandoned, however, because of the political turmoil and was taken up again in 1949, with the establishment of a center at the newly founded Renmin University, one of the Chinese universities that are mainly dedicated to the SSH. Today, the China University of Political Science and Law is working with Sapienza University on translating Roman Law into Chinese (Jun Xue 2016, 509): the Corpus Iuris Iustinianeum translation into Chinese, Luoma fa 罗马法, which has made considerable progress (Schipani 1991-2001, 2001-2021; Wang Zhenmin 2006; Colangelo 2015; Raini 2015), going well beyond the existing information based on the first English translation of the Corpus Iuris edited by Thomas Collett Sandars (1853). Not only have sixteen volumes been published so far (Schipani 1994, 2001; see Colangelo 2015), but most importantly, Chinese terms have been charged with new, more precise meanings. However, the Luoma fa 罗马法 does not offer users any interface and remains instead on published volumes on paper, which means it is not open for annotation and represents only an initial stage of implementing the alignment of translations among corpora. As regards philosophical terms, Timon Gatta has pointed to the linguistic-lexical development of modern Chinese, which the gradual introduction of Western philosophical production, especially through published translations, has enriched with new terms: the main issue being "to adequately conform the new discipline [of philosophy] to East Asia's millennial philosophical speculations about religion, moral habits, political and social behavior" (Gatta 2020, 193-194).

The use of Western categories for explaining Chinese thought and culture to the Western public might bring about the unwelcome effect of distorting or decontextualizing a figure or text (Bodde 1955; Hamburger 1956). In the past centuries, we can say that Chinese scholars had worked with a pragmatic attitude before the Western world, in the sense that although they did not have a genuine interest in Western culture, they studied it nonetheless to import the things that were useful to them. As expressly explained by an official of the highest level of the Qing Dynasty, Zhang Zhidong 张之洞 (1837-1909), the fundamental basis ought to remain Chinese culture, and the Western elements are considered beneficial (zhong ti xi yong 中体西用). Taking up, e.g., Western Civil Law was part of an attitude that has dominated the mentality of the ruling class in China until a few years ago. Nevertheless, slowly, this attitude has been losing influence because, after forty years of rapid economic development, no one seriously thinks that China is still under the threat of the Western world. The strategic position of China has changed, naturally changing the Chinese vision of the Western world. Currently, explains Xue Jun 薛军, “it is thought that China with European countries and all other countries, constitute a human society, within which China is a 
member of equal standing and equal dignity compared to all others.” The Western world "is not an object to be learned, but a companion to study, and the reason for this type of study is to proceed in a more constructive dialogue to achieve mutual understanding between China and the Western world.” In today's globalized world, then, "inter-cultural understanding is the fundamental basis for collaboration” (Xue Jun 2016, 510 - 511).

Looking from another standpoint, Zhao Tingyang 赵汀阳 (2009) has argued that the all-under-heaven (tianxia 天下) mindset, the Chinese view of the world, would be superior to the three Western approaches that most resemble it, namely, first, the idea of the Roman Empire, which relied on military conquest; second, Christian universalism, which tried to solve political problems through religion; and third, Immanuel Kant's perpetual peace, which-says Zhang Feng 张锋 - “smacked of unilateral cultural imperialism.” Thus, all-under-heaven (tianxia 天下) might be put forward as contributing to a sustainable world order insofar as it "envisions a world system characterized by harmony and cooperation without hegemony." The result would be a mindset whose coherence "is maintained through the internal harmony of diversity" (Zhang Feng 2010). This being said in the context of China, one of the countries that claim, together with Russia, the principle of non-interference by states in the internal affairs of another state which is a pillar of the concept of Westphalian sovereignty. Li Tieying 李铁映 noted that at the end of the Ming Dynasty and the beginning of the Qing Dynasty (around the turn between the sixteenth and the seventeenth century), when European culture began to spread to China: "Chinese intellectuals boldly absorbed the foreign culture, and an exchange of ideas between China and the West was gradually realized. Chinese philosophy was able to communicate with Western philosophy, and intellectual history developed into history of philosophy” (Li Tieying 2016, 2).

\subsection{Rendering, Polishing, Transferring}

As regards translation studies, one might say that today translation has risen to the rank of an independent philosophical category (Diagne 2019). History of philosophy requires critical editions along with hermeneutics for text interpretation, while translation studies require attention to history and trust (Rizzi et al. 2019). A translation "is always an interpretation, as shown by the connection of terms with the synonymic values interpretari, vertere, and transferre" (Gregory 2012, 4). Today, research infrastructures such as CLARIN, DARIAH, and OPERAS make it possible to reenact the activity of translating in a powerful way. In this context, the ground-breaking element lies in letting corpora talk to each other (see above 
chapter 7), for corpora are instrumental for innovative ways to come up with traditions.

History of philosophy faces the challenge of dealing with multilingualism. Today it is all the more necessary to consider texts among different languages. This requires innovative approaches and methods for the study of traditional and recent corpora. Historians of philosophy should take our global world into account. Bilingual or multilingual historians of philosophy have today intercultural communication as their primary object.

At issue is creating a multilingual textual database knowledge extraction program for enabling context-guided lexical analysis in the form of an openended knowledge-based architecture for providing access to datasets while including corpora into the LLOD cloud. ${ }^{119}$ For instance, in the context of the cultural exchange between China and the West, historians of philosophy can play a significant role, notwithstanding the difficulties of engaging with the mutual textual legacy. We are talking of momentous cultural exchanges that raise awareness of the need for a culturally sensitive approach to different traditions, including challenges related to cultural and religious diversity.

Tradi, perpoliri, transferre are terms that express Cicero's commitment to bringing over philosophical texts from Greece to Rome. They are the foundation pillars of the translatio studiorum from Greek to Latin, which lasted for centuries. Transferre and translatio lie at the root of neosemic creativity: under certain conditions, writes Quintilian (1920), "necesse sit transferre aut circumire” (De institutione oratoria XII, 10, 34). Tullio Gregory $(2012,6)$ has suggested one could inscribe in the hendiadys transferre aut circumire the history of all problems related to translating. Boethius was well aware of this-and with him Cassiodorus-in the decades that saw the rise and the fall in the Latin West of that final renaissance of Hellenism, which marked the sunset of the ancient world.

An interesting example is the ERC-AdG-2009 project led by Cristina D’Ancona, "Greek into Arabic: Philosophical Concepts and Linguistic Bridges" (G2 A), ${ }^{120}$

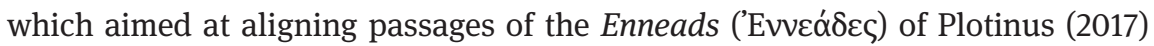
with its Arabic translation performed during the ninth century known as Theologia Aristotelis. From the point of view of sociolinguistics, of particular interest are the sentences of the original text difficult to be understood by those who lived and were formed in a different cultural environment and who, moreover, were dedicated to conveying ideas, philosophical concepts, moral and religious principles from one culture to another (Bozzi 2015). G2A is meant to develop a

119 https://linguistic-lod.org, visited on 6 May 2021.

120 http://www.greekintoarabic.eu, visited on 6 May 2021. 
research interface with functionalities for parallel view and search via the $G 2 \mathrm{~A}$ Web App (a resource offered at the ILC4CLARIN Knowledge Center). ${ }^{121}$

\subsubsection{Translation Group}

Imagine a group of students at a North-American Graduate School of Philosophy who are worried about having to pass the German Language Exam, which is an indispensable requirement if they want to write on a German-speaking author. The picture is not unusual when one thinks of many challenging German-speaking philosophers-Leibniz, Kant, Fichte, Hegel, Schelling, Marx, Nietzsche, Freud, Heidegger, and Wittgenstein -who are the subject of considerable numbers of doctoral theses in North America.

After all, the translation group is about fostering bilingualism, in this case from English speakers to German speakers, not to mention the even higher goal of achieving multilingualism. Bilingual or multilingual historians of philosophy-especially speakers of Arabic, Chinese, German, English, French, Italian, Portuguese, Russian, Spanish, as well as of Hebrew, Greek, and Latin (Cassin 2004)-are still far too few today (Pozzo 2020).

\subsubsection{Clockwise Translating}

Students are aware of the general objection that ideas cannot be translated once and for all since they are tied to the language and culture that identifies with them. We know the remarks of Hans-Georg Gadamer and Reinhart Koselleck that philosophy lives from a language that is continuously in motion. Consequently, philosophy intends to clarify certain concepts historically and renew the tension of thought that manifests itself in the breakpoints of the philosophical usage that the term stands for (Koselleck 1972-2004). The legitimization of conceptual history (Begriffsgeschichte) as philosophy lies exactly in these meaning shifts, the fractures in which the relationship between concept and concept is called into question, and everyday words are artificially transformed into new terms (Gadamer 1970, 147). Hans-Georg Gadamer made the point that:

121 http://www.greekintoarabic.eu; https://g2a.ilc.cnr.it/Teologia_Wapp/Home.xhtml, visited on 6 May 2021. 
The concept of philosophy is not yet applicable to the great answers that the advanced cultures of East Asia and India have given to questions of humanity, as they are repeatedly asked in Europe by philosophy. (Gadamer 1993, 68)

Students may say that philosophy is suitable for multilingual semantics experiments because of its substantial lexicon, which results from centuries of codification. For example, a text string in the ancient Greek alphabet, such as recog-

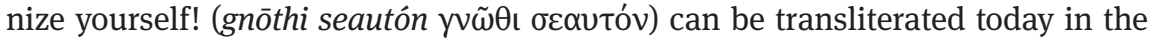
Roman alphabet and, due to the constant development of Unicode, produce new reliable transliterations. Bronisław Malinowski claimed that culture "as the widest context of human behavior, is as important to the psychologist as to the social student, to the historian as to the linguist. I submit that the linguistics of the future, especially as regards the science of meaning, will become the study of language in the context of culture” (Malinowski 1944, 5). And Tullio Gregory made it clear that in this perspective, "neologic invention takes up a central role. The same happens to neosemy, namely the meaning shifts of a word, not only concerning the translated text but also about the need to transcribe new experiences of thought” (Gregory 2012, 4).

Let us go back to our seminary room. Imagine a table and twenty chairs. The instructor sits at the head. Each student has a photocopy of the German original of, say, $\S 15$ of the Transcendental Deduction of the second edition of the Kritik der reinen Vernunft (B129). The instructor has brought his/her copy of the Philosophische Bibliothek edition by Raymund Schmidt (Kant 1956, 137-138). Some students have brought along the English translations by Norman Kemp Smith (Kant 1929, 151-152; see also Palmquist 1995) and Paul Guyer (Kant 1998, 245 246). The instructor starts by translating the first sentence from full stop to full stop, a sentence of four lines (AA3: 107[11-14]; CE [KrV] 245): "Das Mannigfaltige der Vorstellungen kann in einer Anschauung gegeben werden ... wie das Subjekt affiziert wird." Then it is up to the first student sitting at his/her left to translate the following sentence, to his/her misfortune a difficult one (AA3: 107[14-25]): "Allein die Verbindung (coniunctio) ... ein Actus seiner Selbsttätigkeit ist." The second student to the left takes up the third one, this time a simple one (AA3: 107[25-30]): “Man wird hier leicht gewahr ... hat gegeben werden können.” It is then the turn of the third student going around the table clockwise, and the fourth and so on for full two hours of translation working group-clockwise pericope to pericope. Nobody is writing. Twenty heads are figuring out together how

122 "Der Begriff der Philosophie ist noch nicht auf die grossen Antworten anwendbar, die die Hochkulturen Ostasiens und Indiens auf die Menschheitsfragen, wie sie in Europa durch die Philosophie immer wieder gefragt werden, gegeben haben.” 
to understand the sense of and figure out the reference in English to Kant's German sentences. The student whose turn it is to lead speaks first, but everybody is welcome to help him/her out if s/he is looking for words. Dictionaries are at times looked at, but twenty minds find acceptable wordings most of the time without consulting them. An English sentence is being constructed piece by piece. Everybody follows its construction and memorizes it. The corresponding proposition floats in the air. Most participants are satisfied with their comprehension level, although nobody takes care to write down in English the result. The translations of Kemp Smith and Guyer are eventually looked at just to make sure how far the group has deviated from high standards of correctness. The exercise aims not to provide a new translation but rather to break one's mind to understanding Kant's German (Pozzo 2020, 323-326).

Let us consider the general objection that ideas are non-translatable as they are tied to the language and the culture that identifies with them. Hans-Georg Gadamer has made it clear that philosophy issues from the life of language, which is continuously operating. Philosophy does not only:

intend to clarify historically certain concepts but to renew the tension of thinking manifest in the breakpoints of philosophical linguistic use, in which the effort of the concept is refuted. These breakpoints, in which the relation between the term and the concept is questioned, and everyday words are artificially transformed into new conceptual expressions, are the authentic legitimization of the history of concepts as philosophy. (Gadamer 1970, $147)^{123}$

It is not possible to translate terms that "do not allow" translations, i.e., terms that are intraduisibles (Cassin 2004), such as spirit/Geist/espirito/esprit (Benjamin 1923, viii), to say nothing of the endeavor of identifying them with the Chinese jingshen 精神 and tian 天, the latter being part of the anthropocosmic tianrenheyi 天人合一, the unity of heaven and humanity because Confucian philosophy is inspired by a cosmological and anthropological vision and is, therefore, not anthropocentric (Tu Weiming 2010, 181). On the one side, we have texts and terms; on the other, ideas and problems. Hence the necessity to interrogate texts among different alphabets.

123 "Die Philosophie beabsichtigt demzufolge nicht nur, bestimmte Begriffe historisch zu klären, sondern auch, die Spannung des Denkens zu erneuern, die sich an den Bruchstellen des philosophischen Sprachgebrauchs manifestiert, an denen der Begriff steht. Solche Bruchstellen, an denen das Verhältnis zwischen Begriff und Begriff in Frage gestellt wird und die Alltagswörter künstlich in neue Begriffsausdrücke umgewandelt werden, sind die authentische Legitimation der Begriffsgeschichte als Philosophie.” 


\subsubsection{Centrality of Text}

For graduate students of philosophy, the centrality of the text they have chosen to submit to close reading is a shared value (Pasquali 1988). In our imaginary Graduate School, the German Language Exam consists of translating half a page of a writing by Kant. The students who have participated in the translation workgroup benefit from it substantially, for not only were they broken into Kant's German, which was the impulse they needed; they also realize the liberality of what they did, for they did it voluntarily. It was a trial they have submitted to, which they have done out of respect. The students who have taken the translation working group are now more robust.

In recent decades, scholarship has increasingly become aware of links connecting early Greek Classical thought with the ancient Near East culture, whereby languages and translations have been given particular attention. This includes ancient comparisons between Greek and barbarian languages (Ademollo 2011), colonization and subalternity (with their cultural, but also eco-

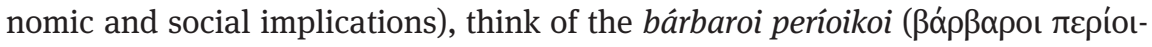
кoı) considered by Aristotle (1855) in Politica VII, 10-1330a25-31 (Zuchtriegel 2017). Classical Greek culture survived in the Middle Ages thanks to the mediation of the Syrians, whose knowledge was recovered and exported to Europe by the Arabs. Reactions and contaminations of these encounters brought innovation and transformation into European culture. One might think of Erasmus, Montaigne, Bruno, Gentili, and other sixteenth- and seventeenth-century authors on issues related to geographic discoveries and forced evangelization. In the eighteenth and nineteenth centuries, we see Leibniz (2002) considering China, Goethe (1819) writing the West-oestlicher Diwan, together with new ways of looking at world peace by Kant and on world history by Hegel (Bonacina 2015).

\subsection{Aligning Kant's Writings and Translations}

The question now is when and why our students will consider the advantages of shifting from the close reading of texts to the distant reading of corpora, following some suggestions laid out by Franco Moretti (2013). For example, thanks to the distant reading of the Kant-Index (Hinske 1982-2020), we know that what makes the Wiener Logik particularly interesting is its proximity to the Kritik der reinen Vernunft. Norbert Hinske has found several verbatim quotes from the first Critique, especially from the Transcendental Theory of Method. For example, in the Wiener Logik, the sentence "There is another world concept" (B 866, AA3: 542[23]; CE [KrV] 694) is quoted: "But one also has a philosophy ac- 
cording to a conceptu cosmico" (AA24: 798[9-10]). ${ }^{124}$ Hinske has noted that the Latin adjective "cosmicus" does not appear in any other text of Kant's logic corpus. The term Logik shows a high-frequency in the list of the most frequently used lemmata in the Logik Pölitz but is much less used in the Wiener Logik, while the term Vernunftlehre completely disappears. In this way, the KantIndex allows a reconstruction of the history of the logic corpus in the decisive years after the publication of each edition of the Kritik der reinen Vernunft (Hinske 1999).

Due to the celebrations of the tercentenary of Kant's birth, the history of the editions of his work is expected to reach a turning point in 2024 when the BerlinBrandenburgische Akademie der Wissenschaften (BBAW) and the De Gruyter publishing house will present the completed new edition of the published writings, i.e., volumes 1-9 of the Academy Edition (NAA; Kant $2021 \mathrm{ff}$.; see Gerhardt 2007; Karl 2007; BKGE 2016).

The editions sponsored by the BBAW started with the Aristotelis Opera edition of Immanuel Bekker in the nineteenth century (continued by Olof Gigon in the twentieth century), which was followed-among others-by the editions of Leibniz and Wilhelm von Humboldt. In 1894, Wilhelm Dilthey initiated the Academy Edition of Kant's Works (AA; Kant $1900 \mathrm{ff}$.), intending to provide access to reliable and complete texts for scholars and students. At Dilthey's time, the Kant-Kommission (of the predecessor of the BBAW) asked the editors to iron out most orthographic and syntactic variants. Since Kant's orthographical habits-so argued the editors of the first volume of the Druckschriften that appeared in 1902-are neither systematic nor consequential, the Kant-Kommission thought better not to disturb most readers with the desuete forms (AA1: 513). Hence, Kant's works from 1747 onward were rewritten using the language of the Kritik der reinen Vernunft, with the result that Kant's polygraphy was completely lost.

Restoring Kant's Urtext requires the closest attention for annotation so that the surface text does not lose anything of the original richness while giving account for historical usages, with deeper layers that offer standardized tokens for horizontal investigation. Hence, before going into alignment issues, it is first necessary to open up Kant's re-established polygraphy for systematic text analysis of conceptual networks, which is now feasible, for the AA-thanks to the efforts of the De Gruyter publishing house-has been reset for the NAA as XML files and offers rich material for experimenting with reflected text analytics and machine learning.

124 "Es giebt aber noch einen Weltbegriff (conceptus cosmicus)"-"Man hat aber auch eine Philosophie nach einem conceptu cosmico." 
For this reason, the first move of the editors of the NAA was submitting queries to CLARIN's historical corpora to check Kant's polygraphy and see whether variants were in use at the time. In our work for the NAA, Hansmichael Hohenegger and myself have found numerous examples of Kant's polygraphy. Let me mention the many cases of oscillating ortography such as ascendat/adscendat, caussa/causa, Cirkul/Cirkel, drücken/drucken, excentum/exemptum, exsistentia/ existentia, Heerde/Herde, kömmt/kommt, promptus/promtus, siehet/sieht, soepenumero/saepenumero, sumptum/sumtum (AA1: 514-516). The AA accounts neither for oscillations in the use of $v$ and $u$ as in vniuersalitas/universalitas nor in the use of $f$ and $s$ as in vniuerfalitas. Also interesting is Kant's consistent usage of quum for causality and of cum for togetherness, which marks a grammatical difference, although it does not belong to Classical Latin. Finally, the AA irons out most capitalizations that Kant evidently uses to stress the meaning of the term as a terminus technicus (Hohenegger 2020), as it was pointed out already by Johann Joachim Lange $(1734,372)$.

Today, editors who must decide about reading the word as a typo or leaving it in the text on its own account use CLARIN's historical corpora such as the Latinize corpus ${ }^{125}$ and the Deutsches Textarchiv (1600-1900), ${ }^{126}$ as well as obviously the DWDS (Digitales Wörterbuch der deutschen Sprache), ${ }^{127}$ and among its tools the DTA-CAB (Deutsches Text-Archiv Cascade Analysis Broker). ${ }^{128}$ Being users of CLARIN means having access to a whole intangible network of knowledge with specific areas of expertise, ${ }^{129}$ especially to parallel corpora insofar as they serve for training data. Parallel corpora are the largest among the CLARIN resource family and are central to translation studies and contrastive linguistics. Many of them are accessible through easy-to-use concordancers that considerably facilitate the study of interlinguistic phenomena. CLARIN provides access to eighty-six parallel corpora, the majority of which are available for download from national repositories as well as through concordancers such as Korp, Corpuscle, and KonText. Currently, CLARIN offers access to forty-seven bilingual corpora, mostly containing European language pairs but also non-European languages such as Hindi, Tamil, and Vietnamese. Thirty-nine corpora are multilingual, with five containing texts in more than fifty languages. Almost half of

125 https://lindat.mff.cuni.cz/repository/xmlui/handle/11372/LRT-3170, visited on 6 May 2021.

126 https://clarin.bbaw.de:8088/fedora/objects/dta:3503/datastreams/cmdi/content?asOfDate Time $=2019-09-30$ T09:20:47.158Z, visited on 6 May 2021.

127 https://www.dwds.de, visited on 6 May 2021.

$128 \mathrm{https} / / /$ kaskade.dwds.de/ moocow/software/DTA-CAB/, visited on 6 May 2021.

129 https://office.clarin.eu/v/CE-2017-1093-ValueProposition-update2020.pdf, visited on 6 May 2021. 
the corpora are sentence-aligned, which allows for easy comparative research (Pozzo et al. 2022b). ${ }^{130}$

Historians of philosophy use the CLARIN resource families for combining data from diverse linguistic resources by maximizing reuse and exploitation of datasets, fulfilling the tenets of the data principles to be findable, accessible, interoperable, and reusable (FAIR) in technical and multiple user-centric perspectives. While considering the corpora that are already part of the CLARIN resources families, however, one cannot help seeing the amount of work that still is to be done for Chinese, which is present, e.g., in MultiUN (Multilingual UN Parallel Text 2000-2009). ${ }^{131}$

In sum, historians of philosophy should begin to realize that among text corpora exists a circularity of which they might benefit from the perspective of intercultural research and communication. The application of language mega-corpora has contributed to the compilation of Chinese dictionaries, either in paper or electronic form, for native and non-native language learners and users. However, the difficulty remains in defining lexical units, for Chinese has no clear rules to segment words into data. Due to this reason, both character dictionaries and word dictionaries exist for Chinese (Shanghai Times 20210). In this direction, the already mentioned translation project of the Corpus Iuris Civilis Digesta into Chinese-Luoma fa 罗马法-has made it possible to charge many Chinese characters with new precise meanings (Schipani 1991-2001, 2001-2021). ${ }^{132}$

\subsection{Looking for the Third Code}

Translating philosophy is an endeavor that will be increasingly carried out over the next few years with the help of electronic data processing. Let us first consider the progress achieved so far in the NAA. The corpora set-up provides an interactive framework for text analysis that combines advanced machine learning techniques, which respond even to subtle patterns in the textual context of terms, with the background knowledge of scholars and their analytical insights. In such a layout, concept modeling can complement established approaches to the history of concepts with novel empirical insights when applied to aligned parallel corpora of texts that have played a vital role in the history of ideas-

130 https://www.clarin.eu/resource-families/parallel-corpora, visited on 6 May 2021.

$131 \mathrm{http} / / /$ www.euromatrixplus.net/multi-un/, visited on 6 May 2021.

132 http://www.odc.uniroma2.it/, visited on 6 May 2021. 
as it is the case, e.g., for Kant's work and its translations, augmented with corpora of secondary research literature from various traditions.

The idea is to think about tackling the challenge of setting up in the form of aligned corpora the NAA and its Chinese translation (Li Qiuling 2003-2019), thus opening the way to further alignments such as with the Cambridge Edition of the works of Immanuel Kant (CE; Kant 1992-2020; Guyer and Wood 1992), the Russian translations coordinated by the Institute of Philosophy of the Russian Academy of Sciences (Tuschling and Motroshilowa 1994), and many other translation endeavors (Schlüter and Hohenegger 2020). However, because not many aligned corpora exist that connect German and Chinese, in this chapter I remain focused on Kant in Chinese.

In this perspective, Chinese offers a particularly challenging state of the art. Some sinologists, first and foremost Marcel Granet $(1968,7)$, have maintained that the difficulty of mutual understanding between Western and Chinese cultures might lie in the impossibility of Chinese to express logically defined and precisely circumscribed concepts that are necessary for philosophical arguments. However, current understandable and faithful Chinese translations of many Western philosophical works-and the translation of Kant's works by Li Qiuling's 李秋零 $(2003-2019)$ is certainly one-show that this assumption is incorrect and biased by cultural preconceptions. This is where the idea of the alignment shows its added value insofar as it is about pushing forward computational concept modeling with reference to Kant's terminology in a validated Chinese translation.

It is quite interesting to consider how the alignment of corpora impacts the so-called Western Grammar in Contemporary Chinese (xiandai Hanyu ouhua yufa 现代汉语欧化语法) (Masini 2009, 648-650; see Tsien Tsuen-Hsuin 錢存訓 1954), which has been proven to cause not only terminological enrichment but also significant modifications-both morphological and syntactic-of Chinese grammar. We are talking of momentous cultural exchanges that raise awareness of the need for a culturally sensitive approach to different traditions, including cultural and religious diversity challenges.

All translations are likely to show specific linguistic characteristics only by virtue of being translations, characteristics that are caused in and by the process of translation. The effect of the source language on the translation is strong enough to make the translated language perceptibly different from the target native language. Consequently, translational language is at best an unrepresentative particular variant of the target language (McEnery and Xiao 2007). Translational language (Translationese) entails the elimination of ambiguities regarding the choice of one word over another. It has four core patterns of lexical use: a relatively lower proportion of lexical words over function words, a relatively 
higher proportion of high-frequency words over low-frequency words, a relatively more significant repetition of the most frequent words, and a smaller vocabulary (Xiao et al. 2010).

From the point of view of translation theory, we can encode a source language (German) through the translational language (machine-operated) to a target language (Chinese) to be decoded. Vice-versa is a feasible possibility. We know of two types of translation universals (Mauranen 2007): one that shapes the process from the source to the target text (S-universals), while the other ( $\mathrm{T}$ universals) compares translations to other target-language texts. The distinctive features of translational language can be identified by comparing translations with comparable native texts, thus throwing new light on the translation process and helping to uncover translation patterns, i.e., what William Frawley (1984) has called the third code of translation.

Translating Western philosophy into Chinese is a complex phenomenon that involves the linguistic-lexical development of modern Chinese by means of the gradual introduction of Western philosophical production, especially through published translations (Masini 1993). For example, Timon Gatta has presented a selection of exemplary concepts that attest to the formation process of China's philosophical lexicography (Fan Bingqing 1926; Rosemont 1974; Shanghai Times 2010). Western philosophical terms have reached standardized translations in Chinese through similar and at the same time different paths of explicitation, simplification, normalization, sanitization, and leveling out. Think for instance of the long history that has led to establishing the current Chinese terms for logic (luoji 逻辑), metaphysics (xing er shang xue 形而上学), and aesthetics (meixue 美学) (Kurtz 2011; Gatta 2020).

Translating Kant into Chinese offers a striking visualization of a third code in motion by means of increasingly successful adaptations of translated language to the native language. As Timon Gatta has explained, the lexical renderings (phonetic loans or semantic loans) of Western concepts that Chinese translators have experimented with over the centuries were initially incapable of adequately expressing the richness of meanings and nuances of the original language. Given the difficulty of Chinese to embrace words from other languages, however, translators have been forced step by step to look for one or two-character words that recall the original meaning of the foreign term, often with results that are anything but satisfactory (Gatta 2021, § 2.2.2). For example, if the rendering of intellect (Verstand zhixing 知性), has been established in all translations of Kant's Critiques of the past fifty years (Gatta 2021, 2021, § 2.2.1), the rendering of phenomenon (Erscheinung xianxiang 現象) shows a different story, for it was seemingly established very early but underwent recent oscillations with for example Li Qiuling (2003-2019) who established a character that includes the meaning 
of appearing, of showing itself, or even more the translations of transcendental (transzendental xianyan 先验) (Gatta 2021, § 3.2.3), which sparked a debate both in Japan and China during the first decades of the twentieth century and even now finds different opinions about it (Gatta 2021, § 2.2.7). The few dozen cases in which Kant uses Phänomen/Erscheinung for actually meaning a "surprising case" in the context of the antinomic nature of the higher faculties complicates the translation but helps to refine the terminological analysis (Hohenegger 2020, $346-349)$.

\subsection{Corpora in Translation Studies}

Corpora work in synergy with dictionaries. More precisely, corpora can function as either general or specialized dictionaries. In this way, comparable corpora can be seen as a monolingual dictionary, while parallel corpora can be compared to a bilingual dictionary. A bilingual dictionary's primary aim is to help the user establish a link between a lexical unit in the source language and its equivalent in the target language. In a bilingual dictionary, the headword is usually defined in the target language. In most cases, a definition is only partially equivalent to the headword because it is often an abstract generalization of the word's typical meanings instead of covering all of its meanings fully (Zanettin 2014). The point is: somebody in between ought to be aware of both traditions. It is corpora that talk to each other, not merely individual philosophers born in different parts of the world.

Along with a general ontology, scholars use narrower domain source ontologies. These more specific ontologies can be bibliographic, specifying the different types of sources used by the community (commentary, articles, critical editions, etc.) or conceptual, embracing the terminology used by determinate authors or constellations of authors (D’Iorio 2015, 7). The alignment itself can be anchored on the existing anchor points: in the paratext, the pages, and the lines of the AA and NAA; and in the text itself, its pericopes and periods. Tools that can be used are unsupervised sentence aligners for symmetrical and asymmetrical parallel corpora. A parallel corpus is a collection of electronic texts assembled according to explicit design criteria aimed at representing a larger textual population. It offers:

a repertoire of translation strategies past translators have resorted to when confronted with similar problems to the ones that have prompted a search in a parallel corpus. A parallel corpus can provide evidence of how actual translators have dealt with this lack of direct equivalence at word level.... Learning to use corpora as translation resources should also 
be part of the curriculum of future translators and become part of their professional competencies. (Zanettin 2014)

The alignment of parallel corpora is part of the challenge of how to boost existing research on automated translation. It is important to note that the alignment of two or more philosophical corpora adds substantial amounts of datasets to enable progress in neural machine translation, training, and data development (Xiao and Ming Yue 2009). Today, the role of machine translation in assisting with the translation of literary texts shows both limitations and potentials. A crucial issue in literary translation is that one needs to preserve the meaning (as in other domains such as technical translation) and the reading experience, which means that a literary translator must carefully select from possible options (Toral and Way 2015, 2018).

Current machine translation models are performing only if applied to technical texts containing many repetitions. The translation faithfully replicates the original text in terms of structure, wording, and style. In the case of literary texts, machine translation is much less performing because the adherence to the text structure produces a translational language of its own, which native speakers can hardly understand. Centuries before machine translation, famous historical examples of token-to-token translations are William of Moerbeke's translations of philosophical, medical, and scientific texts from Greek into Latin, especially of many works by Aristotle, which he did at the request of Aquinas between 1253 and 1286. William's translations were literal (de verbo in verbo), faithful to the spirit of Aristotle and without elegance, i.e., without any attempt at diminishing the impact of both his rudimentary mastering of Greek and of the primitiveness of Medieval Latin philosophical terminology. While William of Moerbeke's Aristotle are texts written in what we call today translational language, the Plato translation from Greek into Latin by Marsilius Ficinus between 1462 and 1484 represents a famous example of a literary translation that is quite close to the native target language. I recall William and Marsilius to make it clear where the challenge lies. Machine translation of philosophical texts today produces William's translational language, which is not enough for historians of philosophy who need boosting machine translation so that it pushes the third code to mold the translation into the native language, i.e., as close as possible to the results achieved by Marsilius.

A close study of the Chinese translation of Kant's writings is useful in gauging the reception of Kant's thinking within the horizon of Chinese semantics. Aligned corpora are also useful for the study of the mechanics of translations into very different linguistic environments, which could eventually be instrumental for computer-based translations. Their most precious added value lies in mak- 
ing available easy access to validated translations of complex texts, thus empowering Chinese readers with automatically generated references for words, whose translation and definition they might have to look for in glossaries or vocabularies, "because graphically, the term would not contain any clue as to its meaning” (Gatta 2021, § 2.2.2; see Fan Bingqing 1926).

Orientation among CLARIN corpora, lexica, and tools includes the Sheffield Corpus of Chinese Annotation (of the Oxford Text Archive), ${ }^{133}$ GATE (General Architecture for Text Engineering), ${ }^{134}$ and the BilingBank (of TalkBank). ${ }^{135}$ Problems arise in using computers in translation, as the computer is no substitute for traditional tools such as monolingual and bilingual dictionaries, terminologies, and encyclopedias on paper or in digital format. Although one can easily access a large amount of information, one needs to find the right and reliable information. One has to consider several variables like the directness of translation, the number of languages, etc. Researchers and students currently use many corpora available in presently operating SSH e-platforms and research infrastructures. Users are "figuratively speaking, facing the shelves of our digital library and can observe how ontologies may help to dynamically arrange the books according to the lenses we use to perceive them. What about opening the books? What happens when we start to navigate not only in the library but in the documents contained in the library?" (D'Iorio 2015, 9)

A great challenge remains the protection of datasets under intellectual property rights (IPR). On top of boosting Kantian philosophical reception in China, straight from German into Chinese, the Kant alignment might achieve impact by enhancing cultural exchanges between China and the West with a highly demanding philosophical background, by providing in-depth analysis of the translation process while fostering advances of machine translation, by influencing debates in political philosophy, metaphysics and philosophy of language and, in linguistics, natural language processing, and last but not least by reaching out to communities of practices that receive and confer datasets and tools to the research infrastructures such as CLARIN. As Martin Wynne has made it clear: CLARIN is "keen to deal with all non-European languages, including major world languages such as Arabic, Chinese, Russian, Japanese, etc."136

Summing up, when I propose to look into corpora talking to each other (see above chapter 7), I am aware of the objection that a corpus does not talk, but

$133 \mathrm{https://ota.bodleian.ox.ac.uk/repository/xmlui/handle/20.500.12024/2481 \# ,} \mathrm{visited} \mathrm{on} 6$ May 2021.

134 https://gate.ac.uk, visited on 6 May 2021.

135 https://biling.talkbank.org, visited on 6 May 2021.

$136 \mathrm{https} / / /$ www.clarin.eu/blog/users-clarin-who-are-they, visited on 6 May 2021. 
only human beings talk who are reading and understanding texts that belong to a corpus. The anthropomorphism is charming. However, it must not cover up crucial details in the act of encoding that links the texts supposedly in conversation, namely the embedding of assumptions and implicit interpretations that in making the possible talking prejudices it. Users must understand what annotation entails, the discipline it imposes, the cautions it requires by anyone using the results, and the amount of actual critical work to be done on text analysis, concept modeling, so-called machine learning, etc. The case for extensive application of CLARIN corpora and tools on this scale is the occasion to consider their potentially illuminating limitations.

\subsection{The Future of Reading}

Federico Zanettin has noted that the translator's workplace has changed in recent years as personal computer information is easier and faster than ever before (Zanettin 2014). Similar translation working groups as the one I have imagined above for the Kritik der reinen Vernunft might be easily organized also for Aristotle's Ethica Nicomachea (2009) or the Meditationes Metaphysicae of Descartes (1993) on behalf of English-speaking students wishing to break their bones on, respectively, Greek and French. I am talking of canonic books. Think of the medieval auctores octo (Curtius 1948, 35; 2013, 119), a collection of Latin textbooks of an elementary standard that includes Dionysius Cato (third-fourth century $\mathrm{AD}$ ), the pseudonym Theodulus, the pseudonym Facetus, Bernard of Cluny (twelfth century), the pseudonym Floretus, Matthew of Vendôme (twelfth century), Alan of Lille (1128-1202/03), and Aesop translated by Gualterus Anglicus (fl. 1175). Of this collection, which according to Ernst Robert Curtius was printed no less than twenty-five times at the dawn of the art of printing, i.e., between 1490 and 1500, Rabelais made fun in Gargantua et Pantagruel (chapter 14). China too has canonic books, the celebrated four classics Analects (Lunyu i仑 语), Doctrine of the Mean (Zhongyong 中庸), Great Learning (Daxue 大学) and Mencius (Mengzi 孟子), and the early historical narratives Discourses of the States (Guoyu 国语), Chronicles of Zuo (Zuozhuan 左传), and Strategies of the Warring States (Zhanguoce 战国策). Later imitations of the classical style, used in literature and formal writings from the third century to the early twentieth century, are said to be written in Literary Chinese (wenyanwen 文言文, “literary text," also referred to as wenli 文理 by Biblical scholars).

In China, the classical versus literary divide is in many ways similar to the relationship between Classical Latin and Medieval Latin in Europe. Think of Boethius when he set the conditions for a bilingual understanding of Aristotle, and 
he did so in classical Latin, ignoring the corrupt forms of the Latin of use spoken at his time in the sixth century. Think of the author or the authors who wrote the so-called Theologia Aristotelis in the ninth century and did the same for Aristotle in Arabic. Descartes translated himself from French into Latin. Leibniz translated himself many times from Latin into French and vice-versa and possibly sometimes also from German into either French or Latin. Pierre Coste translated Locke into French. Kant translated himself into Latin, and Johann Heinrich Tieftrunk translated Kant's Latin back into German. The attempt to translate Kant into Latin failed (Kant 1796-1798). Soon, attempts were made to translate him into modern languages, the first into French as early as 1788 (Müller and Pozzo 1988). In all these cases, we see two forms of the same learned languages, the latter of which emulates the more consistent grammar and lexis of the former. How such a procedure might look in the end is open to discussion.

The group that calls itself The New Humanities Project is looking into the transition space and the platform that makes it possible to experience "new research methodologies and teaching curricula that would question the present epistemological order of the European university system" (Fiormonte et al. 2014, 415; see Gottschall 2008). For it is the media that:

determine and organize memory and its practices, the collective and even more the personal. Each dominant medium with its codes imposes itself as a metaphor of memory. The ever-present danger is that a medium might restrain and regiment memory as imaginative capacity, which constructs knowledge about the past, necessary for the present. The danger is already to be seen in Plato's [1925] Phaedrus [274c-277a], which opposed memory understood as storehouse of data and memory as process of reminiscence, which is always creative. (Fiormonte et al. 2014, 425)

The Stavanger Declaration concerning the Future of Reading states that: "Paper and screens each afford their types of processing. In today's hybrid reading environment of Paper and screens, we will need to find the best ways to utilize the advantages of both Paper and digital technologies across age groups and purposes." ${ }^{137}$ Natalie Philipps and Franco Moretti have been pioneers in designing an experiment with functional magnetic resonance imagery to test "the existence of a neurophysiological basis for Engelsing's typology of extensive and intensive reading” (Moretti 2013, 159; see Engelsing 1974).

137 https://ereadcost.eu/wp-content/uploads/2019/01/StavangerDeclaration.pdf, visited on 6 May 2021. 